\title{
KAJIAN LITERATUR: STUDI PEMETAAN SISTEMATIS INDIKATOR INOVASI SEKTOR PUBLIK
}

Lesmana Rian Andhika
Analis Kebijakan Pemerintah Daerah Kabupaten Aceh Tenggara
lesmana.ra@ outlook.co.id

Diterima: Februari 2020; Direvisi: Maret 2020; Disetujui: April 2020

\begin{abstract}
The public sector innovation indicator essentially simplifies and facilitates communication to achieve a goal. Public sector innovation can be assessed from productivity and dynamics performance, but public sector innovations at the most abstract level, associated with public sector authorities and legitimacy. Therefore, some academic studies are published to provide further knowledge of how public sector organizations act as learning and improvement tools. The purpose of this study is to further explore the results of previous studies relating to public sector innovation and various indicators using a systematic mapping study A systematic mapping study (SMS) is used as a research method to arrange, explain, and research evidence catalog. This research article results in some information i.e., first, assessment of public sector innovation indicators generally uses the interpretation of the private sector concept. Second, a comparison of public sector innovations is used to view or act on diffusion innovations. Third, government intervention and policy in public sector innovation give the idea that innovation activities continue to be the main agenda of the government.
\end{abstract}

\section{Keyword: Indicators, Innovation, Public Sector}

Abstraksi. Indikator inovasi sektor publik pada intinya menyederhanakan dan memudahkan komunikasi untuk mencapai tujuan. Inovasi sektor publik dapat dinilai dari produktivitas dan dinamika kinerja, namun inovasi sektor publik pada tingkat yang paling abstrak, terkait dengan otoritas sektor publik dan legitimasi. Oleh sebab itu berbagai kajian akademis dipublikasikan untuk memberikan pengetahuan lebih lanjut bagaimana organisasi sektor publik berperan sebagai alat pembelajaran dan perbaikan. Tujuan penelitian ini untuk menelusuri lebih jauh hasil penelitian terdahulu yang berkaitan dengan inovasi sektor publik dan berbagai indikator dengan menggunakan systematic mapping study (SMS). Systematic mapping study (SMS) digunakan sebagai metode penelitian untuk menyusun, menjelaskan, dan membuat katalog bukti penelitian yang tersedia. Artikel penelitian ini menghasilkan beberapa informasi yaitu, pertama penilaian indikator inovasi sektor publik umum nya menggunakan interpretasi konsep sektor swasta. Kedua, perbandingan inovasi sektor publik digunakan untuk melihat atau melakukan tindakan difusi inovasi. Ketiga, intervensi pemerintah dan kebijakan dalam inovasi sektor publik memberikan gambaran bahwa kegiatan inovasi terus menjadi agenda utama pemerintah.

\section{Kata kunci: Indikator, Inovasi, Sektor Publik}

\section{PENDAHULUAN}

Studi tentang inovasi telah menjadi bagian penting dalam dekade terakhir, teori inovasi sebagian besar di bentuk dari studi inovasi berbasis teknologi di sektor manufaktur, namun diterapkan dalam semua konteks (Kattel, Cepilovs, Lember, \& Tõnurist, 2019). Pada awal nya inovasi yang sebenarnya adalah sebuah aplikasi di bidang ekonomi dan bisnis, dari teori yang 
lebih luas tentang bagaimana perubahan evolusioner terjadi di masyarakat. Dengan sifat kebaruan yang melekat pada inovasi memberikan arah tindakan yang sering tidak konvensional. Oleh para praktisi dan akademisi telah memetakan apa saja yang menjadi defenisi dan kategori inovasi, setidaknya terdapat enam puluh (60) definisi dan kategori (lihat lebih lanjut Baregheh, Rowley, \& Sambrook, 2009).

Oleh sebab itu kesuksesan sebuah inovasi terletak pada keterbukaan terhadap sudut pandang alternatif. Di sisi yang lain inovasi tidak disajikan sebagai sarana untuk menentukan inovasi berhasil atau tidak. Namun filosofi inovasi (inovasi sektor publik) akan menyediakan kerangka kerja untuk menilai pendekatan organisasi atau individu untuk inovasi. Inovasi dipandang sebagai pendorong daya saing yang mengarah kepada pembaharuan produk layanan sektor publik (Blok, 2018). Idenya adalah kewajiban negara untuk terus menghadirkan produk dan layanan publik yang inovatif untuk merangsang keadilan dan kesejahteraan bagi seluruh lapisan masyarakat.

Inovasi sektor publik dari waktu ke waktu semakin penting dilakukan untuk menghadirkan berbagai pelayanan publik yang baik kepada masyarakat dan meningkatkan kinerja. Saat ini gerakan reformasi sektor publik diberbagai negara berkembang seperti Indonesia terus dilakukan dengan berbagai kegiatan inovasi. Namun pada inti nya inovasi adalah penemuan ide, cara, pelayanan, proses yang dianggap baru, dan bagaimana inovasi itu dilaksanakan dan dievaluasi terus menerus. Kegiatan inovasi mencakup semua langkah ilmiah, teknologi, organisasi, keuangan dan komersial yang benar-benar mengarah atau dimaksudkan untuk melakukan inovasi (Wisdom et al.,
2014; Agger \& Sorensen, 2016). Seperti fenomena sektor publik lain nya, upaya pengukuran indikator inovasi sektor publik dipenuhi dengan kesulitan, baik konseptual (alat untuk mengukur) dan teknis (bagaimana cara mengukur). Oleh sebab itu diskusi akademik terus berlangsung sampai saat ini untuk melakukan upaya mengukur inovasi dan efek yang ditimbulkan (Kattel et al., 2019).

Di Indonesia berbagai kebijakan telah dikeluarkan oleh pemerintah untuk memberikan kerangka acuan untuk melakukan inovasi. Sebagai contoh Undang-Undang Nomor 23 Tahun 2014 tentang Pemerintah Daerah pada BAB XXI pada pasal 386 menjelaskan bahwa dalam rangka peningkatan kinerja penyelenggaraan Pemerintahan Daerah, Pemerintah Daerah dapat melakukan inovasi. Kebijakan lain misal nya tertuang dalam Peraturan Bersama Menteri Riset dan Teknologi Republik Indonesia dan Menteri Dalam Negeri Republik Indonesia Nomor 03-06 Tahun 2012 tentang Penguatan Sistem Inovasi Daerah, mengisyaratkan pemerintah daerah melakukan berbagai bentuk inovasi dalam aktivitas pemerintah.

Di sisi yang lain untuk menumbuhkan minat institusi pemerintah melakukan inovasi, pemerintah setiap tahun nya melakukan pemilihan "Top 99 Inovasi Pelayanan Publik”. Pada tahun 2019 Kemenpan RB mencatat 1.651 inovasi terdaftar dari berbagai institusi pemerintah telah berpartisipasi untuk menunjukkan berbagai inovasi yang telah dilakukan. Untuk mendorong inovasi disetiap daerah Kemendagri juga mengukur tingkat inovasi disuatu daerah melalui indeks inovasi daerah. Beberapa fakta di atas merupakan respon dari Global Competitiveness Index 2018 yang menempatkan Indonesia pada ranking 45 dan masih dibawah negara 
tetangga Thailand, Malaysia, dan Singapura. Walaupun masih dibawah Thailand, Malaysia, dan Singapura berbagai upaya terus dilakukan pemerintah untuk mendorong berbagai inovasi dalam sektor publik.

Oleh karena itu, tidak hanya pada tolak ukur dalam kegiatan inovasi tapi juga efek dari inovasi mesti mendapatkan kajian secara konprehensif (Cruz \& Paulino, 2013). Inovasi adalah sebuah konsep yang kompleks, dalam literatur studi organisasi inovasi menyoroti sejumlah konsep yang diuraikan sebelum memertimbangkan klasifikasi dan pengukuran inovasi. Inovasi mempunyai proses, di mana ide-ide baru, objek dan praktek diciptakan, dikembangkan atau diciptakan kembali. Terkait dengan indikator inovasi sektor publik beberapa penelitian telah pernah dipublikasikan, seperti Bloch \& Bugge (2013) menemukan kata kunci untuk mengukur indikator inovasi pada sektor publik. Mereka memberikan penjelasan bahwa bagaimana inovasi sektor publik dapat ditangkap dan sejauhmana pengukuran dapat didasarkan pada kerangka kerja yang awalnya dikembangkan dalam konteks sektor swasta. Bekkers \& Tummers (2018) dalam studi nya menemukan saat ini inovasi di sektor publik dipandang sebagai proses terbuka kolaborasi antara pemangku kepentingan di berbagai organisasi. Perubahan menuju pendekatan terbuka dan kolaboratif memiliki konsekuensi untuk studi tentang inovasi dan penilaian indikator proses inovasi. Kattel, et al (2019) menemukan bahwa indikator inovasi sektor publik dapat dilihat dengan menggunakan kerangka evaluasi kerja yang akan menjadi alat evaluasi baik di dalam organisasi sektor publik sebagai alat umpan balik, dan juga untuk evaluasi eksternal dari berbagai inovasi sektor publik.

Walaupun studi terdahulu memberikan informasi yang penting tentang indikator inovasi sektor publik namun sampai saat ini promosi inovasi menjadi fenomena yang relatif baru untuk organisasi pelayanan publik. Akibat nya tidak ada tradisi penelitian inovasi sektor public yang tercermin dalam penggunaan istilah dalam jurnal akademik yang ditemukan di jurnal utama seperti Kebijakan dan Politik dan Administrasi Publik. Ini juga berarti bahwa tidak ada pendekatan pengukuran indikator didefinisikan berlaku umum (Potts \& Kastelle, 2010; Vries, Bekkers, \& Tummers, 2015). Tujuan penelitian ini untuk menggali lebih jauh hasil penelitian terdahulu yang berkaitan dengan inovasi sektor publik dan berbagai indikator dengan menggunakan systematic mapping study (SMS). Dengan SMS diharapkan dapat menyediakan peta literatur yang ada, menggambarkan berbagai indikator inovasi sektor publik yang bermanfaat untuk penggunaan secara praktis dan akademis. Selain itu dalam artikel penelitian ini dapat digunakan sebagai studi awal (prelementary research) untuk mengidentifikasi kesenjangan penelitian (gap) di masa depan. Serta membentuk latar belakang penelitian lebih lanjut untuk mendapatkan wawasan yang lebih kompleks tentang topik penelitian.

\section{METODE PENELITIAN}

Penelitian ini menggunakan systematic mapping study (SMS) yang mana merupakan studi sekunder, dan SMS berakar pada study literature review / SLRs (Kitchenham, et al., 2010). Systematic mapping study (SMS) dikembangkan dalam ilmu-ilmu sosial sebagai tanggapan terhadap kurang nya data empiris ketika 
menjawab pertanyaan penelitian menggunakan metode ulasan sistematis, dan kebutuhan akan metode untuk menggambarkan literatur di seluruh subjek yang menarik (James, Randall, \& Haddaway, 2016). Systematic mapping study (SMS) tidak berupaya menjawab pertanyaan spesifik seperti hal nya tinjauan sistematis, melainkan menyusun, menjelaskan, dan membuat katalog bukti yang tersedia (misalnya data primer, sekunder, dan teoritis) yang berkaitan dengan topik atau pertanyaan yang menarik (Petersen, Vakkalanka, \& Kuzniarz, 2015; James, Randall, \& Haddaway, 2016).

Systematic mapping study (SMS) digunakan untuk menyusun wilayah penelitian, sementara tinjauan sistematis (SLRs) difokuskan pada pengumpulan dan sintesis bukti (Petersen, Vakkalanka, \& Kuzniarz, 2015). Untuk mengidentifikasi bagaimana proses systematic mapping study (SMS) dilakukan (termasuk pencarian, pemilihan studi, analisis dan penyajian data, dll), penelitian ini menggunakan petunjuk SMS yang dikembangkan oleh Catal \& Mishra (2013). Proses review yang digunakan dalam studi ini termasuk tahaptahap planning (perencanaan); execution (eksekusi); dan reporting (pelaporan). Selanjutnya akan dijelaskan bertahap, pelaporan dijelaskan pada bagian hasil dan pembahasan sedangkan tahap perencanaan dan eksekusi dijelaskan sebagai berikut:

\section{Planning (perencanaan)}

Pada tahap ini dibuat secara spesifik pertanyaan penelitian dari topik penelitian yang dipilih, strategi pencarian, kriteria inklusi dan eksklusi, dan ekstraksi data dan metode sintesis.

a. Pertanyaan penelitian (RQ)

RQ 1. apa indikator inovasi sektor publik? b. Strategi pencarian, literatur yang relevan tentang indikator inovasi sektor publik yang dikumpulkan dari beberapa database jurnal seperti Sage Journal, ScienDirect, Wiley Online Library, dan Taylor \& Francis Journal untuk menghindari jurnal bereputasi buruk (predator), dan dibatasi pada tahun pencarian 5 tahun terakhir dari 2014-2018. Search string dalam penelitian ini adalah "public sector innovation" OR "public sector innovation indicators". Seperti yang ditegaskan Kane \& Trochim (2007), Petersen, Vakkalanka, \& Kuzniarz (2015), banyak nya kata kunci pencarian tidak mempresentasikan hasil yang ingin dicapai, tetapi kata "kunci" yang lebih spesifik, berkaitan secara signifikan tentang tema penelitian memudahkan untuk identifikasi tentang topik penelitian. Alasan lain karena waktu pencarian yang terbatas, menginggat kata kunci inovasi dari ke empat database tersebut berjumlah ribuan artikel.

c. Membuat kriteria inklusi dan eksklusi, inklusi utama artikel yang dipertimbangkan masuk sebagai data SMS merupakan artikel yang telah dipublikasikan tentang "public sector innovation" OR "public sector innovation indicators". Sedangkan artikel yang tidak dipertimbangkan masuk sebagai data atau kriteria eksklusi adalah artikel yang tidak berhubungan dengan "public sector innovation" OR "public sector innovation indicators", seperti editorial, berita, ringkasan poster, dan tidak berbahasa Inggris. Bila terdapat 
artikel yang sama maka dipilih yang paling mendekati terhadap topik penelitian ini.

d. Membuat klasifikasi artikel, pengklasifikasian dilakukan secara non-exclusive yang berarti sebagian besar kategori tidak eksklusif (Catal \& Mishra, 2013). Teknik pengklasifikasian jurnal pada Tabel 1. mengacu pada studi yang dilakukan Nakano \& Muniz (2018).

e. Validitas, upaya yang dilakukan untuk memertahankan validasi data yang diperoleh peneliti menghindari publikasi bias terhadap topik penelitian seperti proceeding atau artikel yang diterbitkan pada konfrensi (Catal \& Mishra, 2013). Nakano \& Muniz (2018) mengusulkan cara memilih jurnal atau data publikasi agar memerhatikan latar belakang teoritis, mengidentifikasi kesenjangan dalam literatur, dan mendefinisikan konsep-konsep kunci.

Tabel 1.

Klasifikasi Jurnal

\begin{tabular}{|c|c|c|}
\hline No & Jurnal & Kategori \\
\hline 1. & Penulis, Topik penelitian & $\begin{array}{l}\text { Keterlibatan akademis (expert) dan } \\
\text { tinjauan terhadap literatur tentang } \\
\text { indikator inovasi sektor public }\end{array}$ \\
\hline 2. & Objektif, Pendekatan penelitian & $\begin{array}{l}\text { Jurnal mengusulkan teori, kerangka kerja } \\
\text { tentang indikator inovasi sektor publik, } \\
\text { Kualitatif, kuantitative, dan mixed } \\
\text { method }\end{array}$ \\
\hline 3. & Poin Utama & $\begin{array}{l}\text { Menyajikan kerangka kerja analitis oleh } \\
\text { peneliti berdasarkan tinjauan literatur, } \\
\text { dan menyajikan agenda untuk penelitian } \\
\text { masa depan }\end{array}$ \\
\hline
\end{tabular}

Sumber: Data Sekunder (2019)

Execution (eksekusi)

Pada tahap ini strategi pencarian pada database elektronik dilakukan seperti yang direncanakan. Eksekusi pencarian dilakukan 11-30 September 2019 diilustrasikan pada Tabel 2. dari masingmasing database jurnal yang terpilih. Kemudian jurnal tersebut dipilih secara manual untuk memastikan data yang dipilih sesuai dengan kriteria inklusi dengan cara menganalisis abstrak, hasil dan pembahasan, dan kesimpulan. Disamping itu peneliti juga menelusuri kepakaran peneliti agar kriteria inklusi benar-benar dapat terpenuhi.

\section{HASIL DAN PEMBAHASAN}

Teori klasik inovasi dimulai dari pemikiran "Schumpeterian" yang beranggapan inovasi sebagai dimensi kritis perubahan untuk mengembangkan produk dan proses baru (Sengupta, 2014). Inovasi merupakan respon terhadap perubahan mendasar yang diakibatkan oleh buruk nya kinerja pemerintah dalam memberikan pelayanan publik. Di sisi yang lain institusi pemerintah terus mengembangkan berbagai 
indikator yang dapat menjadi acuan dalam merancang dan melaksanakan tindakan inovasi yang dimaksudkan untuk menghasilkan berbagai perubahan dalam pelayanan publik. Oleh sebab itu untuk menghasilkan wawasan yang lebih komprehensif tentang tema penelitian dengan penelusuran data sekunder, akan dibahas terlebih dahulu tentang teori inovasi sektor publik. Kemudian dihadirkan beberapa temuan systematic mapping study dengan kriteria yang telah dirancang sebelumnya.

\section{Ikhtisar Teori Inovasi Sektor Publik}

Inovasi juga mencakup aspek-aspek adopsi, asimilasi, dan ekploitasi kebaruan sebagai nilai tambah untuk organisasi. Inovasi akan bermakna dan menjadi sukses ketika inovasi pada organisasi menjadi sebuah budaya yang terus dipelihara dan menjadi kebiasaan. Ketika inovasi sudah menjadi budaya yang tertanam, kreatifitas akan tumbuh dan berkembang menjadi role model. Inovasi juga semestinya harus didukung oleh proses, tata kelola yang baik, iklim organisasi yang kondusif, kebijakan, sumber daya, dan sikap pemimpin yang menunjukkan dukungan terhadap inovasi (Merrill, 2015). Di sisi yang lain tidak mudah untuk mengenali potensi dari sebuah inovasi. Arti nya, sebuah inovasi muncul harus mengumpulkan dan memroses informasi untuk memahami alasan di balik inovasi dan aplikasi nya sebagai dasar strategi. Semua strategi merupakan dorongan proses pelaksanaan, memerlukan struktur organisasi, sistem, tata kelola yang tepat, dan orang-orang yang berkompetensi.
Sebuah strategi harus diimplementasikan dengan baik jika manfaat nya dapat direalisasikan. Walaupun terkadang strategi tersebut bertentangan dengan logika manajerial, strategi, struktur, sistem, orang, dan lingkungan (Chau, 2014). Inovasi tidak hanya berfokus pada perubahan konkret dalam hal tertentu yang dihasilkan melalui proses inovasi, tetapi juga pada cara mengelola aktivitas inovasi yang digunakan sebagai standar (Vries, Bekkers, \& Tummers, 2015). Dalam memertimbangkan masa depan inovasi di sektor publik, ada kemungkinan bahwa inovasi akan terus berkembang dengan cara baru yang mengarah kepada inovasi yang lebih sederhana, mudah dipahami, dan murah biaya.

Para akademisi dan praktisi terdahulu telah memberikan penjelasan bahwa inovasi sektor publik mengarah kepada peningkatan kualitas pelayanan publik (Cruz \& Paulino, 2013; Osborne \& Brown, 2013). Oleh sebab itu perlu juga memastikan indikator yang memengaruhi dari inovasi sektor publik (Vries, Bekkers, \& Tummers, 2015; Kattel et al. 2019). Kattel et al. (2019) memberikan cara untuk melihat indikator inovasi sektor publik, pertama kita harus memahami apa sebenarnya inovasi sektor publik (hanya sebagai lawan dari perubahan yang terjadi di organisasi sektor publik). Jika kita tahu bagaimana membedakan inovasi dari non-inovasi di sektor publik maka inovasi di sektor swasta sering diukur melalui berbagai sistem manajemen kinerja, Research \& Development sebagai alat evaluasi untuk menentukan input dan output pengukuran produktivitas. 
Tabel 2.

Klasifikasi Jurnal

\begin{tabular}{|c|c|c|c|c|c|}
\hline No & Database Jurnal & Kata Kunci Pencarian & Terdekteksi & Inklusi & $\%$ \\
\hline 1. & Sage Journal & $\begin{array}{lr}\text { public sector innovation" OR } \\
\text { "public sector } & \text { innovation } \\
\text { indicators" } & \text { [public } \\
\text { administration"] } & \end{array}$ & 158 & 2 & 11,77 \\
\hline 2. & ScienDirect & $\begin{array}{l}\text { public sector innovation" OR } \\
\text { "public sector innovation } \\
\text { indicators" }\end{array}$ & 310 & 8 & 47,05 \\
\hline 3. & $\begin{array}{l}\text { Wiley } \quad \text { Online } \\
\text { Library }\end{array}$ & $\begin{array}{l}\text { public sector innovation" OR } \\
\text { "public sector innovation } \\
\text { indicators" } \\
\text { administration" } \\
\text { management"] }\end{array}$ & 179 & 4 & 23,53 \\
\hline \multirow[t]{2}{*}{4.} & $\begin{array}{l}\text { Taylor \& } \\
\text { Francis Journal }\end{array}$ & $\begin{array}{l}\text { public sector innovation" OR } \\
\text { "public sector innovation } \\
\text { indicators" [ "government" } \\
\text { "public administration"] }\end{array}$ & 62 & 3 & 17,65 \\
\hline & & Jumlah & & 17 & $100 \%$ \\
\hline
\end{tabular}

Sumber: Data Sekunder (2019)

Meskipun telah ada usaha-usaha sebelumnya untuk mengukur inovasi sektor publik, pendekatan sistemik untuk survei inovasi sektor publik mulai muncul selama dekade terakhir (Arundel \& Huber, 2013). Sebagian besar studi tidak mencakup semua kategori dari sektor publik, sebagian besar berfokus pada administrasi publik. Sejumlah lembaga telah melakukan usaha untuk mengukur dan melihat indikator inovasi sektor publik seperti MEPIN (Measuring Publik Innovation in the Nordic Countries), European Public Sector Innovation Scoreboard (EPSIS), Australian Public Sector Innovation Indicators Project (APSII), National Endowment for Science Technology and Arts (NESTA), Korean Government Innovation Index (GII). Sebagai alternatif cara konseptualisasi pengukuran inovasi sektor publik, Kattel et al. (2019) mengusulkan menggunakan kerangka kerja evaluasi.

\section{Pelaporan Systematic Mapping Study}

Pada bagian ini dari hasil penelusuran secara manual data inklusi yang terdeteksi menunjukkan terdapat beberapa bagian yang menjelaskan indikator dari inovasi sektor publik yang diilustrasikan pada Tabel 3.

Pada Tabel 3. memberikan informasi bahwa tinjauan dalam literatur yang terpilih terdapat dua kategori. Dimana masingmasing kategori memiliki peran dan fungsi yang berbeda, misalnya dalam kategori 1 pengelolaan inovasi dalam konsep inovasi dari berbagai pandangan praktisi dan akademisi memerlihatkan bahwa salah satu cara untuk mengelola inovasi perlu strategi. Strategi inovasi tidak lain adalah komitmen yang didasari kepada seperangkat kebijakan, proaktif pimpinan, governansi inovasi, dan budaya inovasi (Merrill, 2015). Strategi yang baik memromosikan keselarasan antara beragam kelompok 
dalam organisasi, memerjelas tujuan dan prioritas, serta membantu memfokuskan upaya yang terus dilakukan. Semua strategi merupakan dorongan proses pelaksanaan, memerlukan struktur organisasi, sistem, governansi yang tepat, dan orang-orang yang berkompetensi. Sebuah strategi harus diimplementasikan dengan baik jika manfaatnya dapat direalisasikan. Walaupun terkadang strategi itu bertentangan dengan logika manajerial, strategi, struktur, sistem, orang, dan lingkungan (Agolla \& Lill, 2013; Chau, 2014; Dong, 2014).
Penelitian yang dilakukan Dolfsma dan Seo (2013) menemukan, teknologi dapat berkembang secara terpisah, terlepas dari pengetahuan spesifik yang telah dikembangkan di masa lalu atau teknologi dapat berkembang secara kumulatif. Karakteristik khusus dari teknologi belum secara signifikan dirangsang oleh pemerintah ketika merumuskan dan menerapkan kebijakan inovasi. Arti nya, kebijakan pemerintah sebagai intrumen dapat merangsang pemanfaatan teknologi dalam inovasi lebih jauh.

Tabel 3.

Tinjauan Terhadap Literatur

\begin{tabular}{|c|c|c|c|}
\hline No & Kategori & Sub Kategori & Penulis \\
\hline \multirow[t]{7}{*}{1.} & Pengelolaan inovasi & $\begin{array}{l}\text { Kolaboratif, } \\
\text { perencanaan }\end{array}$ & $\begin{array}{l}\text { Spies (2014); } \\
\text { Sorensen }(2016)\end{array}$ \\
\hline & & & $\begin{array}{l}\text { Fuente (2013); Spies (2014); } \\
\text { Bartlett (2016) }\end{array}$ \\
\hline & & Teknologi & $\begin{array}{l}\text { (Agolla \& Lill, 2013); Bourke } \\
\text { \& Roper (2017) }\end{array}$ \\
\hline & & Kualitas & (Cruz \& Paulino, 2013) \\
\hline & & Motivasi & Demircioglu \& Audretsch \\
\hline & & Strategi & (2017) \\
\hline & & & Torugsa \& Arundel (2017) \\
\hline \multirow[t]{5}{*}{2.} & Pemerintah & Intervensi & Wang (2018) \\
\hline & & Kebijakan & $\begin{array}{l}\text { Arundel, Casali, \& Hollanders } \\
\text { (2015); Edler \& Yeow (2016); } \\
\text { Guo, Guo, \& Jiang (2016); } \\
\text { Gault (2018); Lane (2018); } \\
\text { (Patanakul \& Pinto, 2014) }\end{array}$ \\
\hline & & Research & \\
\hline & & Development & $\begin{array}{l}\text { Guo, Guo, \& Jiang (2016); } \\
\text { Demircioglu \& Audretsch } \\
\text { (2017); Gault (2018) }\end{array}$ \\
\hline & & $\begin{array}{l}\text { Pengadaan dan biaya } \\
\text { inovasi publik }\end{array}$ & $\begin{array}{l}\text { Edler \& Yeow (2016); Lampe } \\
(2017)\end{array}$ \\
\hline
\end{tabular}

Sumber: Data Sekunder (2019)

Selanjutnya pada kategori 2 peran pemerintah untuk menyediakan inovasi lebih dominan. Inovasi-inovasi yang diadopsi mengembangkan bentuk-bentuk inovasi yang lebih dahulu dilakukan oleh swasta. Karena inovasi sektor publik lebih mendapat perhatian dari pemerintah untuk menyediakannya, inovasi-inovasi tersebut 
sering diatur oleh seperangkat kebijakan mulai dari perencanaan sampai evaluasi. Tidak ada kebijakan publik khusus dan dukungan kebijakan mengakibatkan kesenjangan dan ketidakmampuan untuk mengkonseptualisasikan inovasi sebagai mekanisme yang lebih luas dalam aktivitas pemerintah, sosial-ekonomi dan pembangunan, atau kurangnya penghargaan terhadap peran potensial yang dapat dimainkan inovasi dalam pembangunan (Daniels, Ustyuzhantseva, \& Yao, 2017).

Pemerintah adalah salah satu penentu kapasitas inovasi meskipun peran dan tingkat keterlibatannya dalam inovasi masih bisa diperdebatkan. Intervensi pemerintah dapat menjadi vital dalam mendukung research \& development inovasi karena pemerintah sendiri sering tidak dapat memberikan insentif yang memadai untuk produksi pengetahuan. Akan tetapi, tingkat intervensi pemerintah bervariasi di berbagai negara dan mulai dari intervensi direktif dengan secara aktif memberi saran kebijakan dan berinvestasi di bidang-bidang tertentu, hingga intervensi fasilitatif dengan menciptakan lingkungan positif dan menyediakan barang publik. Misal nya negara Singapura dan Hong Kong sering menggunakan intervensi pemerintah terhadap kinerja inovasi. Singapura dikenal dengan intervensi pemerintah yang kuat sementara Hong Kong terkenal dengan kebijakan non-intervensi yang meminimalkan kekuatan pemerintah dalam memengaruhi kebutuhan inovasi. Lebih jauh dalam praktek industri kegiatan inovasi di Singapura sebagian besar didorong oleh kebijakan dan didominasi oleh pemain besar, sementara di Hong Kong inovasi industri kurang aktif tetapi industri lokal memiliki basis inovasi dinamis yang disumbangkan oleh perusahaan kecil. Oleh sebab itu efektivitas intervensi pemerintah dalam meningkatkan signifikansi teknologi dan ruang lingkup inovasi merupakan implikasi keterlibatan pemerintah dalam inovasi.

Di semua domain, reformasi peraturan harus menghasilkan manfaat dalam hal mengurangi biaya, meningkatkan efisiensi dan merangsang inovasi. Namun, ini harus dilakukan tanpa mengorbankan atau membahayakan tujuan regulasi asli nya. Apakah hal ini terkait untuk memastikan transaksi pasar yang adil, melindungi lingkungan atau memertahankan pengawasan pemerintah terhadap kegiatan sektor swasta. Reformasi regulasi seringkali menimbulkan beberapa penyesuaian jangka pendek, dengan demikian, penilaian efek keseluruhan dari regulasi yang ada harus memiliki pandangan jangka panjang. Reformasi peraturan juga kontroversial dalam mendistribusikan kembali kebijakan publik dan mengubah sistem perlindungan yang sudah ada, baik untuk pemerintah, swasta dan konsumen. Menetapkan derajat dan bentuk regulasi yang tepat merupakan tantangan yang sulit bagi pemerintah dan memiliki implikasi penting bagi proses inovasi dan kemajuan teknologi. Untuk itu reformasi regulasi diarahkan untuk memastikan bahwa regulasi ini tetap sepenuhnya responsif terhadap perubahan kondisi ekonomi, sosial dan teknis di sekitarnya. Dalam beberapa kasus, reformasi peraturan dapat berarti peningkatan daripada penurunan tingkat regulasi atau pengawasan pemerintah.

\section{Objek dan Metode Penelitian}

Strategi, proses atau teknik yang digunakan dalam pengumpulan data atau bukti untuk analisis dengan mengungkapkan informasi baru dengan pemahaman yang lebih baik tentang suatu topik. Oleh sebab itu objek dan metode 
penelitian yang teridentifikasi dari systematic mapping study diilustrasikan pada Tabel 4.

Pada Tabel 4. memberikan informasi bahwa dari 17 jurnal yang teridentifikasi, 12 jurnal diantaranya dilakukan dengan metode kualitatif atau $76,48 \%$, dan hanya 4 jurnal atau 23,52\% dilakukan dengan metode kuantitatif. Hal ini mengandung arti bahwa penyelidikan terhadap "public sector innovation" OR "public sector innovation indicators" terus berkembang dan menjadi minat kajian administrasi publik. Kajian teoritis menjadi dominan dalam metode kualitatif, hal ini memberikan tanda bahwa konsep yang tersedia masih perlu digali dan dipelajari dengan membandingkan inovasi sektor swasta, karena inovasi dan atribut yang melekat masih dominan dilakukan oleh swasta.

\section{Poin Utama Penelitian}

Poin utama dari literatur yang telah teridentifikasi memberikan wawasan dan pemahaman selanjutnya untuk mengambarkan berbagai indikator, mengidentifikasi dari sudut pandang yang berbeda, diilustrasikan pada Tabel 5.

Pada Tabel 5. memberikan informasi bahwa dari jurnal yang teridentifikasi terdapat tiga poin yang paling sering dibahas ketika para akademisi dan praktisi memberikan pandangan melalui penelitian. Pertama, penilaian indikator inovasi sektor publik, hal terjadi karena masih bias nya indikator yang digunakan karena interpretasi konsep sektor swasta. Kattel, et al (2019) memberikan argumentasi bahwa tidak ada indikator yang berlaku universal bagi inovasi sektor publik. Hampir semua studi yang teridentifikasi pada penelitian ini memberikan indikator berdasarkan konseptual penilaian kerangka kerja sektor swasta. Walaupun demikian bagi sebagian akademisi, praktisi dan lembaga, konseptualisasi indikator berdasarkan studi sebelumnya menjadi pilihan utama (Agolla \& Lill, 2013; Bloch \& Bugge, 2013; Kattel, et al. 2019).

Kedua, perbandingan inovasi sektor publik digunakan untuk melihat atau melakukan tindakan difusi inovasi. Pada saat yang sama dasar bukti untuk keberhasilan atau kegagalan inovasi sektor publik sebagian besar terdiri dari studi kasus (OECD, 2019). Ada banyak ulasan sistemik untuk menguraikan faktor yang berbeda dan karakteristik memengaruhi terjadinya inovasi, berkelanjutan dan dampak (Vries, Bekkers, \& Tummers, 2015; Cinar, Trott, \& Simms, 2018).

Ketiga, intervensi pemerintah dan kebijakan dalam inovasi sektor publik memberikan gambaran bahwa kegiatan inovasi terus menjadi agenda utama pemerintah. Studi yang dilakukan Wang (2018) memberikan gambaran, pemerintah adalah salah satu penentu kapasitas inovasi. Intervensi pemerintah dapat menjadi vital dalam mendukung penelitian dan pengembangan inovasi. Akan tetapi, tingkat intervensi pemerintah bervariasi di berbagai negara dan mulai dari intervensi direktif dengan secara aktif memberi saran kebijakan dan berinvestasi di bidang-bidang tertentu, hingga intervensi fasilitatif dengan menciptakan lingkungan positif dan menyediakan barang publik.

Agar pembahasan lebih komprehensif maka dipilih salah satu poin utama penelitian terdahulu yang memiliki bobot persentase paling besar. Artinya bahwa poin utama penilaian indikator inovasi sektor publik $(35,30 \%)$ yang paling banyak bukti yang teridentifikasi. Oleh sebab itu pembahasan poin utama merujuk pada sebuah contoh indikator inovasi sektor 
publik yang dikembangkan oleh Australian Public Sector Innovation Indicators Project (APSII) yang juga ditemukan pada data sekunder secara parsial terdiri dari:

\section{Input to innovation;}

2. Innovation processes;

3. Outputs of innovation;

4. Outcomes of innovation;

5. Environmental condition.

Pengukuran inovasi sektor publik dapat dinilai dari produktivitas dan dinamika kinerja, namun inovasi sektor publik pada tingkat yang paling abstrak, terkait dengan otoritas sektor publik dan legitimasi ( Cruz \& Paulino, 2013; Bloch \& Bugge, 2013; Kattel et al. 2019). Kattel, et al (2019) dalam studi nya menemukan bahwa permintaan politik untuk menilai indikator inovasi sektor publik sangat penting untuk dimulai, memfasilitasi dan mendanai upaya pengukuran yang langsung terkait dengan legitimasi kegiatan sektor publik. Namun, tidak satupun dari upaya pengukuran dapat dikaji terhadap pengaruh inovasi tanpa legitimasi sektor publik dan kepercayaan.

\section{Input to innovation}

Cinar, Trott, dan Simms (2018) menemukan dalam studi nya bahwa ada kebutuhan untuk mengenali kegiatan inovasi yang memiliki pengaruh pada keberhasilannya, juga manajemen proses yang tidak efektif dapat menghambat inovasi. Studi yang lain juga menyarankan beberapa cara praktis seperti bereksperimen berarti melakukan simulasi berbagai kegiatan yang mengarah kepada pilihan inovasi yang tepat (Stewart-Weeks \& Kastelle, 2015). Selain itu kebijakan pemerintah dapat mengintervensi (memajukan atau menghambat) sebuah inovasi (Edler \& Fagerberg, 2017). Inovasi memerlukan investasi yang besar terutama sumber daya dan waktu. Kegagalan ini disebabkan oleh berbagai macam faktor salah satu nya berakar dari kurang nya strategi inovasi dan kebijakan pendukung (Paraskevopoulou, 2012; Patanakul \& Pinto, 2014; Merrill, 2015). Sebagai contoh, karakteristik yang paling sederhana untuk menentukan input inovasi adalah pemanfaatan teknologi. Pemanfaatan teknologi dalam aktivitas pemerintah tidak semata-mata hanya sebagai kebutuhan, tetapi lebih dari pada itu pemanfaatan teknologi akan melahirkan efisiensi. Sistem yang dibentuk dari pemanfaatan teknologi adalah sistem yang berinteraksi dalam area tertentu dan didukung oleh infrastruktur dan upaya-upaya difusi. Banyak contoh di mana pemerintah memanfaatkan teknologi seperti e-government, dan mobile government yang mengharuskan pemerintah berinvestasi. Pada saat yang sama penggunaan teknologi harus didukung oleh sumber daya manusia, dan berbagai kebijakan sehingga penggunaan anggaran tidak menjadi sia-sia.

Kegagalan inovasi pada umum nya dihasilkan oleh pemimpin yang tidak responsif, lemah nya kemampuan manajerial inovasi, sumber daya, dan komitmen dari pemangku kepentingan yang terlibat (Jiang \& Chen, 2016: Bourke \& Roper, 2017; Berman \& Prasojo, 2018). Konsekuensi yang muncul akan menyebabkan tidak ada nya dukungan untuk menetapkan target dan membangun lingkungan yang kondusif dimana inovasi tersebut akan dijalankan. Mekanisme pemantauan dan evaluasi untuk mengukur perubahan dan efektivitas inovasi sering tidak dilakukan, dan tidak adanya sistem penghargaan untuk meningkatkan pemikiran kreatif. 
Tabel 4.

Objek dan Metode Penelitian

\begin{tabular}{|c|c|c|c|c|c|}
\hline No & Objek Penelitian & Metode & Pendekatan & Jumlah & $\%$ \\
\hline \multirow[t]{4}{*}{1.} & \multirow{6}{*}{$\begin{array}{c}\text { "Public sector } \\
\text { innovation" OR } \\
\text { "Public sector } \\
\text { innovation } \\
\text { indicators" }\end{array}$} & Kualitatif & Studi kasus & 4 & 23,53 \\
\hline & & & Kajian teoritis & 6 & 35,30 \\
\hline & & & Kajian Historis & 2 & 11,76 \\
\hline & & & $\begin{array}{l}\text { Komparatif } \\
\text { analisis }\end{array}$ & 1 & 5,89 \\
\hline \multirow[t]{2}{*}{2.} & & Kuantitatif & Survey & 3 & 17,64 \\
\hline & & & Statistik deskriptif & 1 & 5,88 \\
\hline \multirow[t]{2}{*}{3.} & & Mixed Method & - & - & \\
\hline & & & Jumlah & 17 & $100 \%$ \\
\hline
\end{tabular}

Sumber: Data Sekunder (2019)

Tabel 5.

Poin Utama Penelitian

\begin{tabular}{|c|c|c|c|}
\hline No & Poin Penelitian & Jumlah & $\%$ \\
\hline 1. & Perbandingan inovasi sektor publik & 5 & 29,41 \\
\hline 2. & Penilaian indikator inovasi sektor publik & 6 & 35,30 \\
\hline 3. & Konseptual baru & 2 & 11,76 \\
\hline 4. & $\begin{array}{l}\text { Intervensi pemerintah dan kebijakan dalam inovasi sektor } \\
\text { publik }\end{array}$ & 4 & 23,53 \\
\hline \multicolumn{2}{|r|}{ Jumlah } & 17 & $100 \%$ \\
\hline
\end{tabular}

Sumber: Data Sekunder (2019)

\section{Innovation processes}

Proses inovasi berarti penerapan metode produksi atau pengiriman hasil inovasi yang ditingkatkan secara signifikan termasuk perubahan terhadap cara, pengelolaan dan penggunaan peralatan. Karena organisasi publik dapat berinovasi untuk meningkatkan legitimasi dengan cara adopsi atau tidak sepenuhnya mengadopsi inovasi. Dengan demikian, implementasi, penggunaan, dan pengelolaan suatu inovasi adalah aspek penting untuk organisasi publik (Walker, 2014; McLaughlin \& Kennedy, 2016). Selain itu, inovasi tidak selalu harus menggunakan teknologi. Inovasi juga bisa berupa kegiatan pro aktif (jemput bola), lebih berupaya secara langsung berinteraksi dengan masyarakat dengan kegiatan aksi nyata dengan cara yang sebelumnya tidak pernah dilakukan atau pengembangan cara baru dengan mengadopsi dari tempat yang berbeda. Pada umum nya, potensi kreatif domestik yang terfragmentasi dapat dimobilisasi untuk meningkatkan inovasi dalam aktivitas pemerintah (Trojer, Rydhagen, \& Kjellqvistt, 2014).

\section{Outputs of innovation}

Beberapa pandangan yang teridentifikasi seperti Dolfsma \& Seo, (2013); Patanakul \& Pinto, (2014); Bartlett, (2016); Guo, Guo, \& Jiang, (2016); McLaughlin \& 
Kennedy, (2016); Wang, (2018) memberikan argumentasi bahwa inovasi dalam aktivitas pemerintah memberikan banyak keuntungan. Misalnya, inovasi dalam aktivitas pemerintah dapat meningkatkan kualitas pelayanan publik. Argumentasi dari beberapa praktisi dan akademisi menyimpulkan bahwa sektor publik merupakan tujuan politik dan ambisi profesional yang dapat dicapai dengan lebih efektif dengan merangsang inovasi (Agolla \& Lill, 2013; McLaughlin \& Kennedy, 2016). Pada umum nya inovasi sektor publik akan meningkatkan kinerja dan meningkatkan kualitas pelayanan (Cruz \& Paulino, 2013; Osborne \& Brown, 2013). Di sisi yang lain output inovasi dapat menggerakkan elemen sentral dalam pelayanan. Namun output inovasi sering menimbulkan keraguan untuk melakukan studi dan evaluasi inovasi yang berkelanjutan yang diakibatkan oleh kegagalan inovasi dalam memberikan manfaat yang lebih baik.

Semua orang akan setuju bahwa inovasi dapat mengatasi berbagai masalah dalam aktivitas pemerintah. Namun inovasi tidak selalu akan memberikan manfaat yang lebih besar ketika dihadapkan dengan berbagai gangguan dan terkesan seperti sebuah peralatan rusak yang tidak dapat digunakan secara maksimal. Misalnya, inovasi tidak di dukung oleh seperangkat kebijakan sebagai landasan untuk bertindak (Edler \& Fagerberg, 2017). Hal ini dianalogikan sebagai pekerjaan sebuah mesin, ketika mesin sudah tidak mampu memberikan hasil yang lebih besar maka mesin itu perlu diperbaiki. Selain itu, gangguan terhadap inovasi juga dapat berasal dari upaya pengembangan (Sorensen \& Torfing, 2011). Pada titik ini peran kebijakan dominan untuk menjadi dasar memberikan investasi pengembangan inovasi. Lebih lanjut Sorensen dan Torfing (2011) mengklaim, ada kebutuhan akan bentuk pengembangan inovasi dalam sektor publik, karena cara-cara inovasi yang bersifat tertututp (birokratis) tidak menghasilkan kuantitas dan kualitas yang lebih baik. Diharapkan dengan pengembangan yang sistematik dapat memerpanjang masa operasional inovasi.

\section{Outcomes of innovation}

Berbeda dengan inovasi sektor swasta yang menghasilkan produk baru yang lahir dari pengembangan research. Hasil yang didapat dari inovasi sektor publik adalah terletak kepada objek inovasi itu sendiri, bila tujuannya pelayanan maka hasil yang dicapai adalah kepuasan pelanggan (Agolla \& Lill, 2013). Kemudian pada tingkat pegawai (yang melaksanakan inovasi) dapat memermudah kinerja semakin lebih cepat, mudah dan akurat (Arnold, 2014). Organisasi publik perlu mengidentifikasi ide-ide baru, mencoba pendekatan baru dan bekerja dengan cara baru, hal ini akan meningkatkan kepercayaan publik terhadap pemerintah. Studi yang dilakukan Bloch dan Bugge (2013) menyimpulkan, ada kesadaran bahwa banyak inovasi saat ini terjadi di sektor publik, dan upaya yang lebih sistematis dengan memromosikan inovasi untuk mengatasi tantangan ekonomi dan sosial yang dihadapi sektor publik. Oleh sebab itu pemerintah berusaha untuk terus mendukung adopsi inovasi dalam aktivitas nya. Selain dari tujuan meningkatkan kualitas pelayanan, inovasi dianggap bermanfaat untuk mengubah pola interaksi antara masyarakat dan pemerintah.

Selain itu, pengguna dan penerima inovasi tidak hanya masyarakat namun beberapa institusi dan lembaga akan menggunakan hasil akhir dari inovasi. Sebuah inovasi akan menunjukkan pola 
yang bisa diprediksi, diadopsi oleh individu, kelompok, atau intsitusi. Inovasi akan memberikan keuntungan ketika para pengguna menyadari manfaat nya. Namun pengguna dilingkungan pemerintah bersifat holistik dan instruktif yang terkait antara beberapa institusi yang memunyai fungsi tertentu. Kebutuhan inovasi bagi institusi pemerintah sangat krusial saat ini, juga berhubungan dengan modifikasi yang beradaptasi dengan perubahan. Inovasi dicapai dengan menyediakan sesuatu perubahan dari yang asli dan sering terlihat menghasilkan efisiensi, yang mengarah ke ide yang secara signifikan memengaruhi masyarakat umum. Masyarakat adalah target utama inovasi pelayanan, sebagai target dan penerima keuntungan yang di dapat adalah relatif.

Dalam konsep tata kelola pemerintah yang telah berkembang beberapa generasi, partisipasi masyarakat dianggap sebagai pendorong utama untuk berkontribusi, dan juga mengawasi setiap aktivitas pemerintah. Namun penerapan inovasi pelayanan publik dan reformasi menghasilkan dampak positif namun terbatas. Pandangan lain juga mengungkapkan, evolusi bersama dari tata kelola pemerintahan dan inovasi ditunjukkan dengan ada nya transisi dari pendekatan new public management menuju model governance (Assche, Beunen, \& Duineveld, 2014). Oleh sebab itu adanya distribusi pengetahuan dan inovasi menjadi lebih besar diberbagai tingkat organisasi yang berbeda dalam administrasi publik.

\section{Environmental condition}

Seperti misalnya mengelola inovasi pelayanan publik pemerintah, terdapat sebab akibat antara pelayanan publik dan implikasi kebijakan. Oleh sebab itu implikasi kebijakan yang diusulkan harus membantu perumusan strategi dan langkahlangkah untuk lebih meningkatkan penyampaian inovasi layanan dan tata kelola pelayanan publik. Namun inovasi dalam aktivitas pemerintah tidak dengan mudah dapat direalisasikan karena akan dihadapkan pada beberapa elemen yang dapat melemahkan proses inovasi itu sendiri. Beberapa diantaranya seperti kebijakan (Patanakul \& Pinto, 2014), inovasi merupakan tugas pemerintah daerah agar lebih efisien (Bai \& Li, 2011), kemampuan manajerial yang baik dapat dengan mudah memahami sifat dari hambatan inovasi (Damanpour \& Aravind, 2011).

Studi literatur yang dilakukan oleh Cinar, Trott, dan Simms (2018) menemukan bahwa ada kebutuhan untuk mengenali kegiatan inovasi yang memiliki pengaruh pada keberhasilannya, juga manajemen proses yang tidak efektif dapat menghambat inovasi. Studi yang lain juga menyarankan beberapa cara praktis untuk memerkuat inovasi seperti mengelola inovasi sebagai suatu proses, pengelolaan yang baik akan dimanifestasikan dengan serangkaian fungsi manajemen untuk mengerakkan perencanaan sampai pada tahap evaluasi. Bereksperimen berarti melakukan simulasi berbagai kegiatan yang mengarah kepada pilihan inovasi yang tepat (Stewart-Weeks \& Kastelle, 2015).

Indikator-indikator inovasi sektor publik adalah alat yang digunakan untuk mengambarkan atau mengukur sejauhmana inovasi dapat bekerja. Banyak yang berbeda dapat diukur dalam hal layanan yang diberikan oleh pemerintah mulai dari input, sumber daya, proses, keluaran dan hasil atau dampak. Tujuan dari proses ini biasanya terkait dengan ide-ide transparansi, belajar, atau sangsi untuk menunjukkan akuntabilitas di sektor publik. 
Sederhana nya, argumentasi untuk pengukuran didasarkan pada asumsi bahwa "apa yang diukur, dan akan dilakukan" (lihat lebih lanjut (Osborne \& Brown, 2013).

Walaupun sedikit dari jurnal yang teridentifikasi menghasilkan konseptual baru tentang indikator inovasi sektor publik. Demikian pula penelitian terdahulu yang pernah dipublikasikan sudah memadai untuk memberikan pelajaran tentang indikator inovasi sektor publik. Dengan demikian, logika sektor publik untuk memastikan organisasi mengembangkan indikator dan langkah-langkah komparatif, hal itu tidak sepenuhnya ditentukan dalam format saat ini. Dengan basis pengetahuan memungkinkan untuk mengembangkan metrik yang baik dan bermanfaat untuk praktek inovasi jangka panjang (Vries, Bekkers, \& Tummers, 2015; OECD, 2019). Namun nilai indikator dan pengukuran tidak dapat dilihat secara terpisah dari tujuan penggunaannya karena setiap pengguna berbeda, dan kebutuhan mereka juga bervariasi. Oleh karena itu, pemanfaatan indikator adalah apa yang dapat memberikan nilai tertentu. Saat ini, inovasi di sektor publik dipandang sebagai proses terbuka kolaborasi antara pemangku kepentingan di berbagai organisasi. Perubahan menuju pendekatan terbuka dan kolaboratif ini memiliki konsekuensi untuk studi tentang inovasi. Akan menjadi penting untuk menganalisis bagaimana mengaktifkan pemangku kepentingan untuk bergabung dengan proses inovasi.

\section{SIMPULAN}

Indikator dapat menetapkan target dan menjadi standar yang ditetapkan. Juga diakui bahwa diperlukan ada upaya yang lebih sistematis untuk memromosikan inovasi. Walaupun dari database jurnal yang lain diyakini masih banyak membahas tentang indikator inovasi sektor publik. Artikel yang terdeteksi sesuai dengan kriteria inklusi pada umumnya merupakan pengelolaan inovasi sektor publik dengan indikator perencanaan, kolaboratif, teknologi, kualitas, motivasi dan strategi. Namun berbeda ketika inklusi inovasi sektor publik pemerintah, kecenderungan indikator utama mengarah kepada kebijakan. Karena kebijakan merupakan petunjuk bagi pemerintah ketika menjalankan pengukuran indikator, juga berhubungan dengan anggaran termasuk penelitian dan pengembangan. Untuk itu inovasi membutuhkan anggaran yang tidak sedikit untuk memunculkan ide-ide baru inovasi dengan indikator yang berbeda.

Publikasi yang teridentifikasi menekankan indikator kualitatif sebagai tahap awal proses inovasi. Untuk meningkatkan pemahaman lanskap indikator dan untuk melengkapi berbagai tahapan proses inovasi dengan indikator yang relevan diperlukan perlakuan indikator yang konkret untuk meningkatkan keputusan eksekusi inovasi.

Hasil systematic mapping study ini merekomendasikan hal-hal sebagai berikut untuk penelitian masa depan diantaranya 1). Para praktisi dan akademisi yang tertarik pada inovasi harus menghubungkan penelitian mereka dengan aliran literatur lainnya. Dengan cara seperti itu, para praktisi dan akademisi inovasi dapat mengembangkan penelitian yang relevan bagi masyarakat, menelusuri berbagai atribut yang melekat serta pemanfaatannya sebagai tujuan utama dari inovasi; 2). Perlu penelitian lebih banyak tentang indikator inovasi sektor publik, karena hasil penelusuran jurnal yang teridentifikasi terdapat hubungan seperti yang berfokus pada tata kelola jaringan, kepemimpinan 
dan pemikiran desain. Oleh sebeb itu dimungkinkan mengkonseptualisasikan indikator dari berbagai sumber yang relevan; 3). Pengembangan kerangka kerja dan konsep baru, pada dasarnya konsep baru yang tercipta mengindikasikan bahwa terjadi pergeseran pengetahuan sesuai dengan fakta penelitian. Oleh sebab itu perlu diuji secara empiris agar menghasilkan pengetahuan baru.

\section{DAFTAR PUSTAKA}

Agger, A., \& Sorensen, E. (2016). Managing Collaborative Innovation in Public Bureaucracies. Planning Theory, 1-21. doi:10.1177/1473095216672500

Agolla, J. E., \& Lill, J. B. (2013). Public Sector Innovation Drivers: A Process Model. Journal of Social Sciences, 34(2), 165-176. doi:10.1080/09718923.2013.11893128

Arnold, G. (2014). Policy Learning and Science Policy Innovation Adoption by StreetLevel Bureaucrats. Journal of Public Policy, 34(3), 389-414. doi:10.1017/S0143814X14000154

Arundel, A., \& Huber, D. (2013). From too Little to too Much Innovation? Issues in Measuring Innovation in the Public Sector. Urbino: University of Urbino.

Arundel, A., Casali, L., \& Hollanders, H. (2015). How European Public Sector Agencies Innovate: The Use of Bottom-up, Policy-Dependent and Knowledge-Scanning Innovation Methods. Research Policy, 44(7), 1271-1282. doi:10.1016/j.respol.2015.04.007

Assche, K. V., Beunen, R., \& Duineveld, M. (2014). Evolutionary Governance Theory: An Introduction. Heidelberg: Springer Science+Business Media .

Bai, J., \& Li, J. (2011). Regional Innovation Efficiency in China: The Role of Local Government. Innovation: Management, Policy \& Practice, 13(2), 142-153. doi:10.5172/impp.2011.13.2.142

Baregheh, A., Rowley, J., \& Sambrook, S. (2009). Towards a Multidisciplinary Defenition of Innovation. Management Decision, 47(8), 1323-1339. doi:10.1108/00251740910984578

Bartlett, D. (2016). Champions of Local Authority Innovation Revisited. Local Government Studies, 43(2), 1-8. doi:10.1080/03003930.2016.1245184

Bekkers, V., \& Tummers, L. (2018). Innovation in the public sector: Towards an Open and Collaborative Approach. International Review of Administrative Sciences, 84(2), 209-213. doi:10.1177\%2F0020852318761797

Berman, E., \& Prasojo, E. (2018). Leadership and Public Sector Reform in Asia. Bingley: Emerald Publishing Limited.

Bloch, C., \& Bugge, M. M. (2013). Public Sector Innovation-From Theory to Measurement. Structural Change and Economic Dynamics, 27(2013), 133-145. doi:10.1016/j.strueco.2013.06.008

Bourke, J., \& Roper, S. (2017). Innovation, Quality Management and Learning: ShortTerm and Longer-Term Effects. Research Policy, 46(8), 1505-1518. doi:10.1016/j.respol.2017.07.005 
Blok, V. (2018). Philosophy of Innovation: A Research Agenda. Philosophy of Management, 17(1), 1-5. doi:10.1007/s40926-017-0080-z

Catal, C., \& Mishra, D. (2013). Test Case Prioritization: a Systematic Mapping Study. Software Quality Control, 21(3), 445-478. doi:10.1007/s11219-012-9181-z

Chau, D. M. (2014). Administrative Reform in Vietnam: Need and Strategy. Asian Journal of Public Administration, 19(2), 303-320. doi:10.1080/02598272.1997.10800343

Cinar, E., Trott, P., \& Simms, C. (2018). A systematic Review of Barriers to Public Sector Innovation Process. Public Management Review, 20, 1-28. doi:10.1080/14719037.2018.1473477

Cruz, S., \& Paulino, S. (2013). Public Service Innovation and Evaluation Indicators. Journal of Technology Management \& Innovation, 8(ALTEC), 285-297.

Daniels, C. U., Ustyuzhantseva, O., \& Yao, W. (2017). Innovation for Inclusive Development, Public Policy Support and Triple Helix: Perspectives From BRICS. African Journal of Science, Technology, Innovation and Development, 9(5), 513527. doi:10.1080/20421338.2017.1327923

Demircioglu, M. A., \& Audretsch, D. B. (2017). Conditions for Innovation in Public Sector Organizations. Research Policy, 46(9), 1681-1691. doi:10.1016/j.respol.2017.08.004

Dolfsma, W., \& Seo, D. (2013). Government Policy and Technological Innovation-a $\begin{array}{llll}\text { Suggested Typology. } & \text { Technovation, } & \text { 33(6-7), }\end{array}$ doi:10.1016/j.technovation.2013.03.011

Dong, A. (2014). Design $\times$ Innovation: Perspective or Evidence-Based Practices. International Journal of Design Creativity and Innovation, 3(3), 148-163. doi:10.1080/21650349.2014.943294

Edler, J., \& Fagerberg, J. (2017). Innovation Policy: What, Why, and How. Oxford Review of Economic Policy, 33(1), 2-23. doi:10.1093/oxrep/grx001

Edler, J., \& Yeow, J. (2016). Connecting Demand and Supply: The Role of Intermediation in Public Procurement of Innovation. Research Policy, 45(2), 414-426. doi:10.1016/j.respol.2015.10.010

Fuente, J. M. (2013). E-Government Strategies in Spanish Local Governments. Local Government Studies, 1-21. doi:10.1080/03003930.2013.787414

Gault, F. (2018). Defining and Measuring Innovation in All Sectors of the Economy. Research Policy, 47(3), 617-622. doi:10.1016/j.respol.2018.01.007

Guo, D., Guo, Y., \& Jiang, K. (2016). Government-Subsidized R\&D and Firm Innovation: Evidence from China. Research Policy, 45(6), 1129-1144. doi:10.1016/j.respol.2016.03.002

James, K. L., Randall, N. P., \& Haddaway, N. R. (2016). A Methodology for Systematic Mapping in Environmental Sciences. Environmental Evidence, 5(7), 1-13.

Jiang, Y., \& Chen, C. C. (2016). Integrating Knowledge Activities for Team Innovation: Effects of Transformational Leadership. Journal of Management, 44(5), 18191947. doi:10.1177/0149206316628641

Kattel, et al. (2019). Indicators for Public Sector Innovations: Theoretical Frameworks and Practical Applications. Administrative Culture, 19(1), 77-104. 
Kemenpan RB, (2019, Mei 22). Penetapan Top 99 Inovasi Pelayanan Publik Pertimbangkan Opini Masyarakat. Retrieved from Kementrian Pendayagunaan Aparatur Negara dan Reformasi Birokrasi: https://www.menpan.go.id/site/beritaterkini/penetapan-top-99-inovasi-pelayanan-publik-pertimbangkan-opinimasyarakat

Kane, M., \& Trochim, W. M. (2007). Concept Mapping for Planning and Evaluation. Thousand Oaks, CA: SAGE Publications.

Kitchenham, et al. (2010). Systematic Literature Reviews in Software Engineering - A Tertiary Study. Information and Software Technology, 52(2010), 792-803. doi:10.1016/j.infsof.2010.03.006

Lampe, H. W. (2017). Municipalities' Willingness to Adopt Process Innovations: Evidence for Higher Cost-Efficiency. Local Government Studies, 43(5), 1-24. doi:10.1080/03003930.2017.1324428

Lane, A. M. (2018). Regulatory Constraints on Public Sector Innovation: A Case Study on Queensland's Independent Public School Program. Australian Journal of Public Administration, 77(4), 685-699. doi:10.1111/1467-8500.12307

McLaughlin, G. C., \& Kennedy, W. R. (2016). A Guide to Innovation Processes and Solutions for Government. Boca Raton, FL: CRC Press.

Merrill, P. (2015). Innovation Never Stop: Innovation Generation the Culture, Process, and Strategy. Milwaukee : Quality Press.

Nakano, D., \& Muniz, J. (2018). Writing the Literature Review for an Empirical Paper. Production, 28(e20170086), 1-9. doi:10.1590/0103-6513.20170086

OECD. (2019). Observatory of Public Sector Innovation. Paris: OECD.

Osborne, S. P., \& Brown, K. (2013). Introduction: Innovation in Public Services. In S. P. Osborne, \& K. Brown, Handbook of Innovation in Public Services (pp. 1-28). Cheltenham, UK: Edward Elgar.

Paraskevopoulou, E. (2012). Non-Technological Regulatory Effects: Implications for Innovation and Innovation Policy. Research Policy, 41(6), 1058-1071. doi:10.1016/j.respol.2012.03.018

Patanakul, P., \& Pinto, J. K. (2014). Examining the Roles of Government Policy on Innovation. Journal of High Technology Management Research, 25(2), 97-107. doi:10.1016/j.hitech.2014.07.003

Peraturan Bersama Menteri Riset Dan Teknologi Republik Inonesia dan Menteri Dalam Negeri Republik Indonesia Nomor 03-06 Tahun 2012 tentang Penguatan Sistem Inovasi Daerah

Petersen, K., Vakkalanka, S., \& Kuzniarz, L. (2015). Guidelines for Conducting Systematic Mapping Studies in Software Engineering: An Update. Information and Software Technology, 64(2015), 1-18. doi:10.1016/j.infsof.2015.03.007

Potts, J., \& Kastelle, T. (2010). Public sector innovation research: What's next? Innovation: Management, Policy \& Practice, 12(2), 122-137. doi:10.5172/impp.12.2.122

Sengupta, J. (2014). Theory of Innovation: A New Paradigm of Growth. Switzerland: Springer International Publishing. 
Sorensen, E., \& Torfing, J. (2011). Enhancing Collaborative Innovation in the Public Sector. Administration \& Society, 43(8), 842-868. doi:10.1177/0095399711418768

Spies, P. H. (2014). The Democratization of Innovation: Managing Technological Innovation as If People Matter. World Future Review, 6(1), 15-28. doi:10.1177/1946756714522211

Stewart-Weeks, M., \& Kastelle, T. (2015). Innovation in the Public Sector. Australian Journal of Public Administration, 74(1), 63-72. doi:10.1111/1467-8500.12129

Torugsa, N., \& Arundel, A. (2017). Rethinking the Effect of Risk Aversion on the Benefits of Service Innovations in Public Administration Agencies. Research Policy, 46(5), 900-910. doi:10.1016/j.respol.2017.03.009

Trojer, L., Rydhagen, B., \& Kjellqvistt, T. (2014). Inclusive Innovation ProcessesExperiences from Uganda and Tanzania. African Journal of Science, Technology, Innovation and Development, 6(4), 425-438. doi:10.1080/20421338.2014.970437

Undang-Undang Republik Indonesia Nomor 23 Tahun 2014 Tentang Pemerintahan Daerah

Vries, H. d., Bekkers, V., \& Tummers, L. (2015). Innovation in the Public Sector: A Systematics Review and Future Research Agenda. Public Administration, 94(1), 146-166. doi:10.1111/padm.12209

Walker, R. M. (2014). Internal and External Antecedents of Process Innovation: A Review and Extension. Public Manajemen Review, 16(1), 21-44. doi:10.1080/14719037.2013.771698

Wang, J. (2018). Innovation and Government Intervention: A Comparison of Singapore and Hong Kong. Research Policy, 47(2), 399-412. doi:10.1016/j.respol.2017.12.008

Wisdom, J. P., Chor, K. H., Hoagwood, K. E., \& Horwitz, S. M. (2014). Innovation Adoption: A Review of Theories and Constructs. Adm Policy Ment Health, 41(4), 480-502. doi:10.1007/s10488-013-0486-4 